Check for updates

Cite this: RSC Adv., 2017, 7, 24168

Received 6th March 2017 Accepted 27th April 2017

DOI: 10.1039/c7ra02700a

rsc.li/rsc-advances

\section{Synergistic activating effect of promoter and oxidant in single step conversion of methane into methanol over a tailored polymer-Ag coordination complex $\dagger$}

\author{
Raghavendra Shavi, ${ }^{a}$ Vishwanath Hiremath, ${ }^{a}$ Aditya Sharma, (DD b Sung Ok Won ${ }^{b}$ \\ and Jeong Gil Seo (D)*a
}

Single-step conversion of methane to its oxygenated derivatives, such as methanol, is a challenging topic in $\mathrm{C} 1$ chemistry. The presence of Brønsted-acidic sites, $\mathrm{N}$ - and $\mathrm{O}$-type chelating ligands, and noble metals are demonstrated to be essential criteria for effective catalysis of this reaction. Considering these criteria, a catalytic complex was tailored herein. Poly-D-glucosamine (Ch) was used as chelating ligand for Ag, to incorporate the robust redox properties of $\mathrm{Ag}\left({ }^{\prime}\right)$. The prepared $\mathrm{AgCh}$ complex was characterized by techniques including solid-state ${ }^{1} \mathrm{H}-\mathrm{NMR}, \mathrm{FE}-\mathrm{TEM}, \mathrm{XANES}$, and XPS. Besides highlighting the utility of chelate complexation for providing new materials, this study elucidates the effects of the oxidant and promoters on the methane oxidation. The catalytic activity was tested for different oxidant combinations, including hydrogen peroxide, oxygen, and carbon dioxide. Of all of them, a mixture of hydrogen peroxide and oxygen showed the highest selectivity for oxidation of methane to methanol. Further, it was observed that the addition of 1-butyl-3-methylimidazolium chloride $[\mathrm{BMIM}]^{+} \mathrm{Cl}^{-}$as a promoter to the hydrogen peroxide and oxygen-containing AgCh system could enhance methanol production. The methanol yield reached up to $3166 \mu \mathrm{mol}$, representing an 18-fold yield increase and an 8-fold methane conversion increase when compared to the results $(175 \mu \mathrm{mol})$ without a promoter.

\section{Introduction}

Global climate change is an increasingly serious problem resulting from increasing global industrialization and the associated output of greenhouse gases, such as methane $\left(\mathrm{CH}_{4}\right)$. While carbon dioxide $\left(\mathrm{CO}_{2}\right)$ is the major contributor to the greenhouse effect by volume, $\mathrm{CH}_{4}$ is a much more potent greenhouse gas. Thus, strategies to increase the use of waste $\mathrm{CH}_{4}$ gas as a feedstock for the production of industrially important chemicals, such as methanol and acetic acid, are an effective means to reduce harmful $\mathrm{CH}_{4}$ emissions and may reduce the greenhouse effect. Many attempts have previously been made to utilize $\mathrm{CH}_{4}$ in the preparation of syngas, ${ }^{1-3}$ which is a major feedstock for methanol production. However, the formation of the final methanol product requires multiple hightemperature steps and the use of different catalysts of type $\mathrm{Cu}$ / $\mathrm{ZnO} / \mathrm{Al}_{2} \mathrm{O}_{3}{ }^{4,5}$ Consequently, the direct single-step conversion of $\mathrm{CH}_{4}$ to its oxygenates, such as methanol and acetic acid,

${ }^{a}$ Department of Energy Science and Technology, Myongji University, Nam-dong, Yongin-si, gyeonggi-do 449-728, South Korea.E-mail:jgseo@mju.ac.kr

${ }^{b} X$-ray Open Laboratory, Advanced Analysis Center, Korea Institute of Science and Technology, Seoul-02792, South Korea

$\dagger$ Electronic supplementary information (ESI) available. See DOI: 10.1039/c7ra02700a remains a challenge. The inertness of $\mathrm{CH}_{4}$, caused by its high $\mathrm{C}-\mathrm{H}$ bond dissociation energy $\left(\Delta H_{\mathrm{C}-\mathrm{H}}=439.57 \mathrm{~kJ} \mathrm{~mol}^{-1}\right)$, is a key problem that has prevented the use of soft reaction conditions for $\mathrm{CH}_{4}$ conversion, such as low acidity, low temperature, and low pressure. Therefore, catalysts that are tailored to increase the $\mathrm{C}-\mathrm{H}$ bond activity and thereby enable faster reaction kinetics for $\mathrm{CH}_{4}$ conversion, especially to oxygenates, are urgently required.

It is important to understand which properties of catalysts are advantageous for the conversion of $\mathrm{CH}_{4}$ to its oxygenates, as previously investigated by several research groups. ${ }^{6,7}$ Metal complexes have been extensively tested as catalysts for the conversion of $\mathrm{CH}_{4}$ because of their ability to undergo inorganic nucleophilic reactions. Kirillova et al. ${ }^{6}$ tested vanadium-based metal complexes as catalysts in the homogeneous catalytic conversion of $\mathrm{CH}_{4}$ to acetic acid, and found that complexes with more N,O- or O,O-polydentate groups in their ligands showed the best catalytic activity. The use of these ligands enabled a $50 \%$ improvement in the yield of acetic acid. Their report was consistent with previous reports of alkane oxidation reactions in which the N,O-type ligands (N-heterocyclic carboxylic acids) were recognized for their involvement in the proton transfer steps. ${ }^{6}$ Therefore, catalysts with these favorable ligand environments are suitable for further tailoring. The role of the noble 
metal atoms in these catalyst complexes may be understood by considering $\mathrm{Pt}(\mathrm{bpym}) \mathrm{Cl}_{2}$ and $\mathrm{HAuCl}_{4}$ ref. 7 and 8 complexes, which were previously employed for the production of methanol from $\mathrm{CH}_{4}$ in homogeneous systems with a highly acidic solvent medium. While these complexes showed the best catalytic activity for $\mathrm{CH}_{4}$ conversion (TON > 500), the conversion reaction did not reach completion, yielding methyl bisulfate $\left(\mathrm{CH}_{3}\right.$ $\left.\mathrm{OSO}_{3} \mathrm{H}\right)$. The harsh conditions employed in these reaction systems meant they were not investigated further. Since then, trends in the field have shifted towards mimicry of the $\mathrm{CH}_{4}$ monooxygenase (MMO) enzyme, ${ }^{9}$ which oxidizes $\mathrm{CH}_{4}$ to methanol in nature, and the replacement of hard solvents by hydrogen peroxide $\left(\mathrm{H}_{2} \mathrm{O}_{2}\right)$. As an example, the complex [CuICuICuI(7-N-Etppz)]1 $1^{+}$, where 7-N-Etppz stands for the organic ligand 3,3'-(1,4-diazepane-1,4-diyl)bis[1-(4-ethylpiperazine-1-yl) propan-2-ol], was reported by Liu et al. for methanol production. ${ }^{10}$ Based on previous reports of increased yields from zeolite-supported $\mathrm{Cu}$, Fe catalysts, ${ }^{11}$ the [CuICuICuI(7-N-Etppz)] $1^{+}$complex was supported on silica nanoparticles resulting in an increased yield of methanol. However, while the harsh conditions of the earlier reaction systems were successfully replaced, the central aim of achieving a higher $\mathrm{CH}_{4}$ conversion was not addressed. Noble metal complexes that function under milder conditions are yet to be tested and understood. The few reported examples of heterogeneous catalyst systems for $\mathrm{CH}_{4}$ conversion also reveal specific properties of the catalysts. For example, Sun et al. replaced the acidic solvent (sulfuric acid) used in a homogeneous reaction system with a solid acidic catalyst, i.e., a heteropolyacid chemisorbed on silica. ${ }^{12}$ Their study demonstrated and generalized the requirement for catalysts with acidic properties by showing that acidic catalysts convert $\mathrm{CH}_{4}$ to acetic acid under mild conditions. Brønstedacidic groups also play a considerable role in the proton exchange steps involved in producing methanol and acetic acid. ${ }^{13}$ Thus, to reduce the high bond dissociation energy of $\mathrm{CH}_{4}$ and thereby achieve a higher conversion of $\mathrm{CH}_{4}$ to its oxygenates, catalysts should have several N,O-type ligands, high acidity, Brønsted-acidic sites, and be heterogeneously supported. Further, previous reports ${ }^{7,14}$ have shown that the use of inorganic chloride salts as promoters can increase the $\mathrm{CH}_{4}$ conversion. Though activity increased after using promotor, the total conversion of $\mathrm{CH}_{4}$ by mass did not meet the expectations. Weak attraction between the catalyst and the added salt promoter still remains as a drawback in this case. Thus making use of promoting salts that interact strongly with the catalyst, forming an intermediate structure which boosts the kinetics of $\mathrm{CH}_{4}$ conversion is preferable.

Our strategy is to use a biopolymer, poly-D-glucosamine (Ch), to ligate $\mathrm{Ag}$ ions with its $\mathrm{N}$ - and $\mathrm{O}$-based chelating groups. This biopolymer also contains highly acidic Brønsted acid sites, and the regular arrangement of the chelating atoms in Ch enables a systematic arrangement of active $\mathrm{Ag}$ sites for the $\mathrm{CH}_{4}$ conversion reaction. Therefore $\mathrm{Ag}$ coordinated $\mathrm{Ch}$ (AgCh) complex meets all the criteria mentioned above for producing a much higher yield of methanol and is competitive with the performance of other zeolite-based catalysts. We highlight that, unlike with zeolite-supported catalysts, the AgCh catalyst's competitive performance results solely from the active Ag sites, with no contribution from the support. We show that the total TON can be directly correlated to the number of moles of $\mathrm{Ag}$ contained in the catalyst. These observations prove that our tailored catalyst is highly active for the $\mathrm{CH}_{4}$ conversion reaction. We also investigated the effect of halide ion-containing ionic liquids on the reaction, finding that the inclusion of these ionic liquids created a stable intermediate structure that gave $\sim 13$ times greater $\mathrm{CH}_{4}$ conversion. The interaction between the ionic liquids and the catalyst is discussed later in this article. We also prepared $\mathrm{CuCh}$ and FeCh using the same method and compared their performance to that of $\mathrm{AgCh}$ to prove the effect of the noble metal in the AgCh complex.

\section{Experimental section}

\section{Materials and methods}

Silver nitrate $\left(\mathrm{AgNO}_{3},>99 \%\right)$, copper(II) nitrate pentahydrate $\left(\mathrm{CuNO}_{3} \cdot 5 \mathrm{H}_{2} \mathrm{O}, 98 \%\right)$, iron(III) nitrate nonahydrate $\left(\mathrm{FeNO}_{3}\right.$ $\cdot 9 \mathrm{H}_{2} \mathrm{O}$ ), poly-D-glucosamine, and the ionic liquids 1-butyl-3methylimidazolium chloride (>98\%) and 1-butyl-3-methylimidazolium bromide $(>97 \%)$ were purchased from Sigma Aldrich. Sodium hydroxide $(\mathrm{NaOH})$ and hydrogen peroxide $\left(\mathrm{H}_{2} \mathrm{O}_{2}\right)(30 \%)$ were purchased from Sanchun chemicals, Korea. High purity methane (99.95\%) and carbon dioxide (99.999\%) were used for reactions, and high purity hydrogen (99.99\%) and oxygen (99.999\%) were used as standards for gas chromatography (GC) analysis. Double-distilled water was used in all reactions.

\section{Catalyst preparation}

Poly-D-glucosamine (500 mg) was dispersed in double-distilled water $(250 \mathrm{~mL})$ contained in a beaker $(500 \mathrm{~mL}$ capacity). The dispersion was heated to $80{ }^{\circ} \mathrm{C}$ on a hot plate and stirred for $20 \mathrm{~min}$ at $600 \mathrm{rpm}$. Then, the required metal nitrate (Ag, Fe, or $\mathrm{Cu})(5 \mathrm{mmol})$ was dissolved in water $(100 \mathrm{~mL})$ in a separate beaker. This solution was added dropwise to the poly-Dglucosamine dispersion. After a further $10 \mathrm{~min}$, the $\mathrm{pH}$ of the solution was adjusted to 9.3 by the addition of sodium hydroxide with careful stirring, forming the poly-Dglucosamine-metal complex as a solid precipitate. The complex was filtered, washed several times with water, and air-dried. Catalyst with $\mathrm{Ag}, \mathrm{Fe}$ and $\mathrm{Cu}$ are abbreviated as $\mathrm{AgCh}, \mathrm{FeCh}$ and CuCh respectively.

\section{Sample characterization}

Fourier transform infrared (FTIR) spectroscopy was recorded using a Varian 2000 Fourier transforms infrared spectrophotometer by accumulating 32 scans between 2000 and 4000 $\mathrm{cm}^{-1}$. The samples were pelletized with $\mathrm{KBr}$ and put in an FTIR chamber for analysis. X-ray photoelectron spectroscopy (XPS) analyses (ESCALAB 250, UK) were performed under a vacuum of $\sim 1.3 \times 10^{-7} \mathrm{~Pa}$. A monochromated X-ray Al $\mathrm{K}_{\alpha}$ source (energy: $15 \mathrm{kV}, 150 \mathrm{~W}$ ) with $h \gamma$ of $1486.6 \mathrm{eV}$ was used for all measurements. The analyzed area was $400 \mu \mathrm{m}^{2}$. The binding energy values were charge-corrected to the $\mathrm{C} 1 \mathrm{~s}$ signal $(284.5 \mathrm{eV})$. Peak 
deconvolution was performed with XPS peaks 41 software. X-ray diffraction (XRD) spectra were recorded between $2 \theta$ of 10 and $90^{\circ}$. A Cu anode was used, and continuous scans were taken for each sample. Solid-state ${ }^{1} \mathrm{H}$ magic angle spinning (MAS) nuclear magnetic resonance (NMR) spectra were recorded on a Bruker Avance II $+400 \mathrm{MHz}$ spectrometer. The instrument was operated at a rate of $400 \mathrm{MHz}$ with a spin rate of $13 \mathrm{kHz}$. X-ray absorption spectroscopy (XAS) was used to collect Ag, Fe, and Cu K-edge Xray absorption near edge structure (XANES) data, using the labsource R-XAS Looper (Rigaku R-XAS) with a $3 \mathrm{~kW}$ X-ray generator and a Mo- $\mathrm{LaB}_{6}$ target-filament combination. A Johannsontype curved Ge (220) crystal with a Rowland circle of radius of $320 \mathrm{~mm}$ was used in the monochromator section. The incident X-ray intensity $\left(I_{0}\right)$ was monitored using a semi-transmission type proportional counter filled with Ar gas, with Be windows on both sides. Transmitted X-ray intensity $\left(I_{t}\right)$ was measured with a high-speed scintillation counter. Thin layered samples (sandwiched between Kapton tape) were mounted between the $I_{0}$ and $I_{\mathrm{t}}$ detectors, in the transmission geometry. The $\mathrm{Fe}$ and $\mathrm{Cu}$ K-edge energies were calibrated using standard $\mathrm{Fe}$ and $\mathrm{Cu}$ foils, that were measured under the above conditions. Thermogravimetric analysis (TGA), using a TGA N 1000 (SCINCO) thermogravimetric analyser was used to study the degradation patterns of the catalysts. The samples were heated to $600{ }^{\circ} \mathrm{C}$ with a ramping rate of $5{ }^{\circ} \mathrm{C} \mathrm{min}^{-1}$. Elemental analysis was carried out using a Flash EA 1112 elemental analyzer. Samples were dissolved in acetic acid (0.1 M) for analysis. Transition electron microscopy (TEM) images were recorded using a JEOL-200CX. Ion chromatography (IC) was used to analyse products in solution. The method specifications used were: column: Aminex 87H (Bio-rad), high performance liquid chromatography (HPLC): Ultimate 3000 (Dionex, USA), eluent: $\mathrm{H}_{2} \mathrm{SO}_{4}(0.01 \mathrm{~N})$, flow: $0.5 \mathrm{~mL} \mathrm{~min}^{-1}$, oven temperature: $40{ }^{\circ} \mathrm{C}$, and detector: refractive index (RI) (ERC refractoMAX520).

\section{Catalytic activity test}

The catalyst was added to an ice-cooled reactor vessel $(150 \mathrm{~mL}$ capacity) containing double-distilled water $(15 \mathrm{~mL})$ and $\mathrm{H}_{2} \mathrm{O}_{2}(5$ $\mathrm{mL}, 30 \%)$. Thus charged, the vessel's lid was fitted tightly and the vessel was degassed by purging with $\mathrm{N}_{2}$ for $5 \mathrm{~min}$. Then, the reactor was pressurized to the required pressure with $\mathrm{CH}_{4}(\mathrm{~g})$. The system was heated at $60{ }^{\circ} \mathrm{C}$ and electrically stirred at a rate of $900 \mathrm{rpm}$. After attaining the correct temperature, the reaction was allowed to proceed for the required time. After this time, the system was simply allowed to cooldown to room temperature and then cooled with ice to condense the gaseous oxygenated products. The liquid was filtered and the products were analysed by IC to determine the product contents in units of milligrams, from which amount of the product in units of moles was calculated. All results were compared to standards for confirmation. The gas-phase products were analysed by GC (Agilent 7890A TCD/FID). The number of moles of $\mathrm{CO}_{2}$ was calculated from a calibration curve. The $\mathrm{CO}_{2}$ content (mol) was calculated by eqn (1) and (2),

$$
\text { Concentration of } \mathrm{CO}_{2}=\text { peak area } \times R_{\mathrm{f}}
$$

Amount of $\mathrm{CO}_{2}(\mathrm{~mol})=$ concentration of $\mathrm{CO}_{2}$ $\times$ volume of reaction vessel $(\mathrm{mL})$,

where $R_{\mathrm{f}}$ is the response factor.

\section{Results}

\section{Characterization of poly-D-glucosamine-based metal complexes}

The solid-state ${ }^{1} \mathrm{H}$ MAS NMR spectra for the poly-D-glucosamine catalyst and its $\mathrm{Ag}$ coordination complex, $\mathrm{AgCh}$, are shown in Fig. 1. A wide and broad peak was observed from 0 to $20 \mathrm{ppm}$, which clearly indicates the presence of highly acidic Brønsted acid groups with strong hydrogen bonding. The large width of the peak also confirms the presence of several hydrogen atom environments with different electropositivity, which affects the degree of hydrogen bonding. The hydrogen atoms of amine groups also contribute to the peak broadening as the ppm range for $\mathrm{N}-\mathrm{H}$ coupling lies within the range of observed broad peak. After the formation of the AgCh complex, a small shift to lower ppm values over the entire peak range and a decrease in peak intensity were observed.

FTIR spectra were recorded for both $\mathrm{Ch}$ and the $\mathrm{AgCh}, \mathrm{CuCh}$, and FeCh complexes (Fig. 2). The characteristic broad band between 2900 and $3600 \mathrm{~cm}^{-1}$ corresponds to the combined absorptions of $\mathrm{N}-\mathrm{H}$ and $\mathrm{O}-\mathrm{H}$ vibrations. ${ }^{15}$ The peaks in the range $1567-1651 \mathrm{~cm}^{-1}$ are assigned to $\mathrm{N}-\mathrm{H}$ deformational vibrations. After the addition of the metals to $\mathrm{Ch}$, a decrease in the intensity of the absorbance between 3400 and $3600 \mathrm{~cm}^{-1}$, assigned to $\mathrm{N}-\mathrm{H}$ vibrations, was observed. This decrease indicates the complex of the metal since the donation of electrons from nitrogen to metal weakens the $\mathrm{N}-\mathrm{H}$ bonds. Complexation of the metal is further confirmed by the disappearance of the weak band at $1567 \mathrm{~cm}^{-1}$, associated with $\mathrm{N}-\mathrm{H}$ vibrations, and a shift in the peak at $1651 \mathrm{~cm}^{-1}$. A sharp peak at $524 \mathrm{~cm}^{-1}$, usually assigned to ligand-to-metal bonding, was also observed in all metal complexes, further confirming the complexation of $\mathrm{Ch}$ with metals. No marked changes in the absorbance of $\mathrm{O}-\mathrm{H}$ bonds were observed. The crystallization behavior of $\mathrm{Ch}$ and the

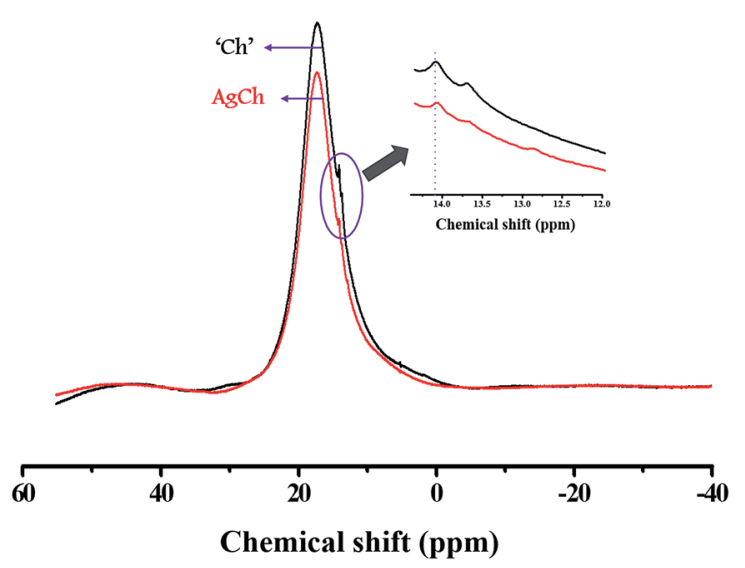

Fig. 1 Solid-state ${ }^{1} \mathrm{H}$ MAS NMR spectra for Ch (black line) and AgCh (red line). 


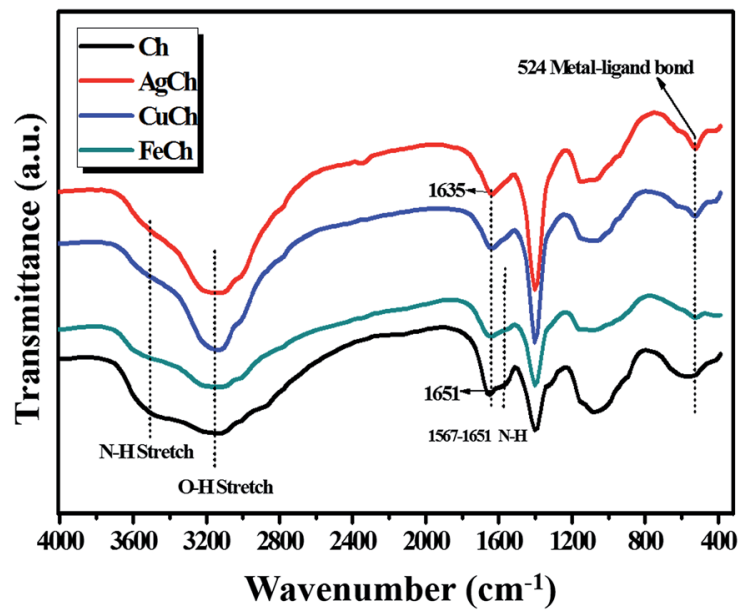

Fig. 2 FTIR spectra for Ch and the different catalyst species.

prepared catalysts was studied using XRD, and the spectra are shown in Fig. 3(a). The pristine $\mathrm{Ch}$ showed a broad reflection at $2 \theta=22.9^{\circ}$, which implies that pristine $\mathrm{Ch}$ is amorphous. After the complexation, this broad reflection sharpened and shifted to $2 \theta=20^{\circ}$, indicating higher crystallinity after complexation of $\mathrm{Ch}$ with metals. No reflections corresponding to the metals were observed in the complexed $\mathrm{Ch}$, suggesting that the metal atoms are only present as chelates, rather than metal particles. The crystalline structure varied between each of the three complexes, with the $\mathrm{FeCh}$ complex showing the sharpest reflection, with the sharpness decreasing in the order of $\mathrm{AgCh}$ followed by CuCh. Fig. 3(b) shows the Ag L1-edge XANES of the $\mathrm{AgCh}$ catalyst. The peak at $\sim 3808.7 \mathrm{eV}$ corresponds to the transition from core $2 \mathrm{~s}$ orbital to the unoccupied p-type orbitals, which occurs at a higher energy in the $\mathrm{AgCh}$ than the corresponding peak in metallic Ag foil $(\sim 2.6 \mathrm{eV})$. Based on this difference in energy, we tentatively suggest that the complexed $\mathrm{Ag}$ is present in the +1 oxidation state, as $\mathrm{Ag}^{+}$ions, although the low Ag content in the AgCh sample and low spectral resolution introduce noise into the presented spectra which may slightly affect the reported energies. This XAS evidence for the presence of $\mathrm{Ag}^{+}$in the $\mathrm{AgCh}$ complex is complemented by the XPS results for $\mathrm{Ag}$ (see below), which also suggest the presence of $\mathrm{Ag}(\mathrm{I})$ in the sample. Fig. 3(c) shows the Fe K-edge XANES spectra for both the reference foil and FeCh. The pre-edge feature, the energy shoulder at $7122 \mathrm{eV}$, and the white line intensity of the $\mathrm{FeCh}$ spectrum indicate that the electronic structure of $\mathrm{FeCh}$ is different to that of the Fe foil. The diverse spectral features of $\mathrm{FeCh}$ are similar to those previously reported for iron oxide, especially $\mathrm{Fe}(\mathrm{II})$ oxide, ${ }^{16,17}$ indicating the presence of $\mathrm{Fe}^{2+}$ ions in the FeCh samples. The Cu K-edge XANES spectra for both $\mathrm{CuCh}$ and $\mathrm{Cu}$ foil are shown in Fig. 3(d). The CuCh XANES spectrum exhibits pre-edge spectral features indicative of $1 \mathrm{~s}-3 \mathrm{~d}$ transition..$^{18}$ The spectral features of the CuCh sample match previously reported spectra of $\mathrm{CuO}$ and $\mathrm{CuS}$ compounds, ${ }^{19}$ suggesting that $\mathrm{Cu}^{2+}$ ions are present in the sample. Each of our samples showed a shift in the white line to a slightly higher energy, compared to their respective metallic foils, which previous reports attribute to the fractional oxidation of $\mathrm{Fe}^{20}$ and $\mathrm{Cu}^{21}$ atoms in the samples. Fractional oxidation is expected to (a)

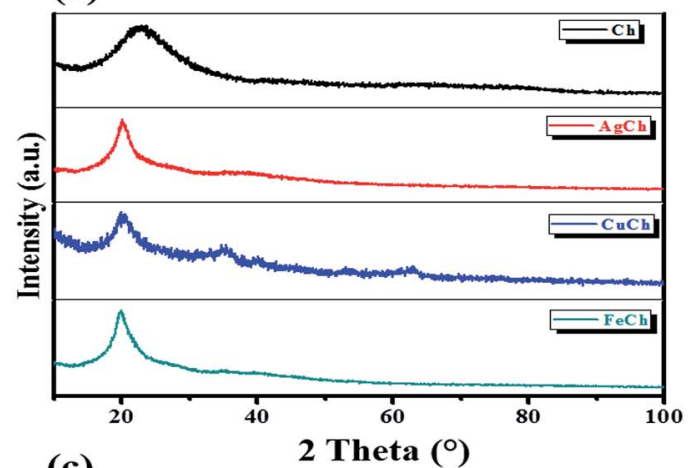

(c)

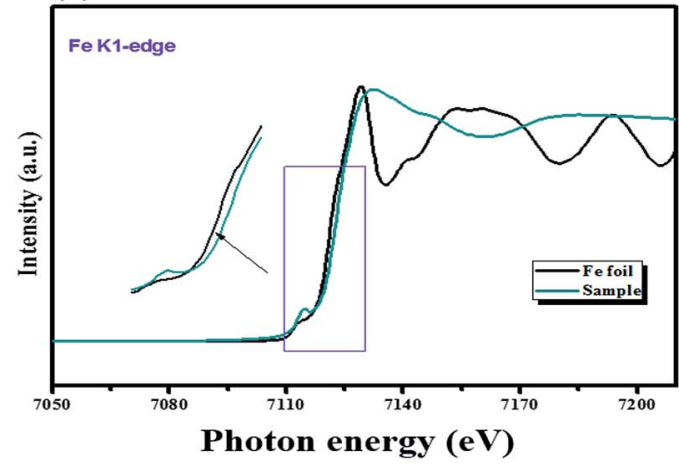

(b)

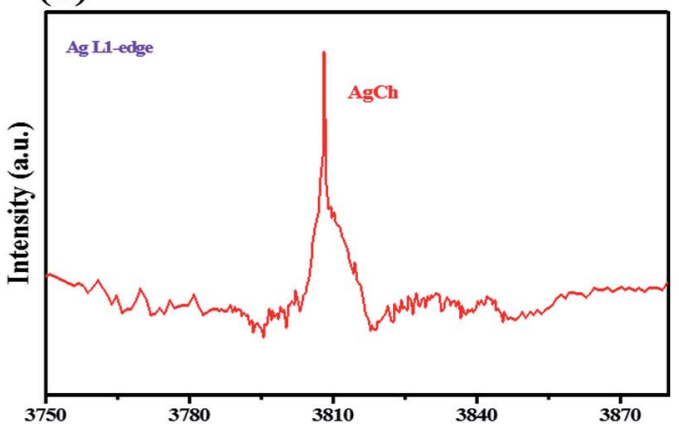

(d)

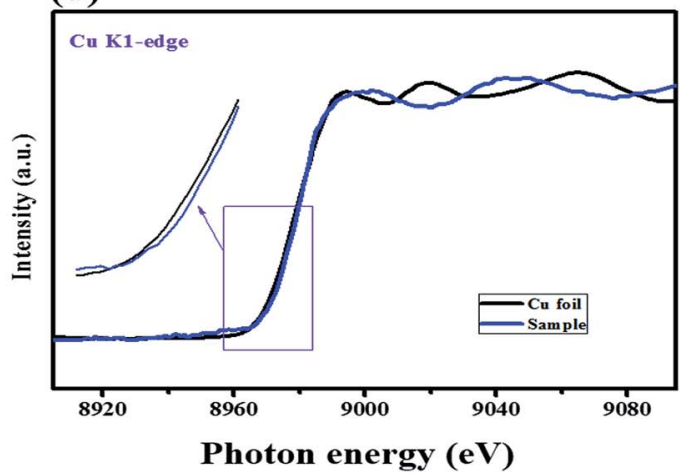

Fig. 3 (a) XRD spectra and (b-d) XANES spectra for $\mathrm{AgCh}$, FeCh, and CuCh respectively. 
(a)

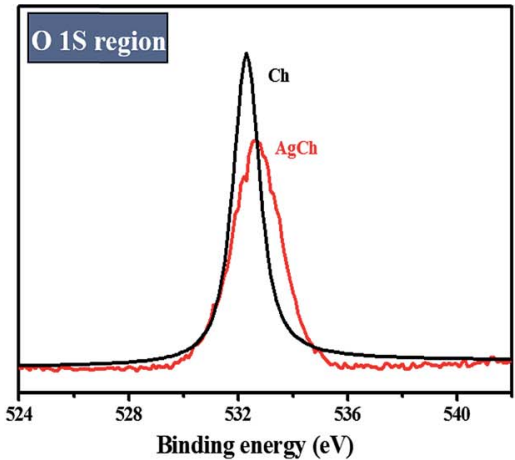

(b)

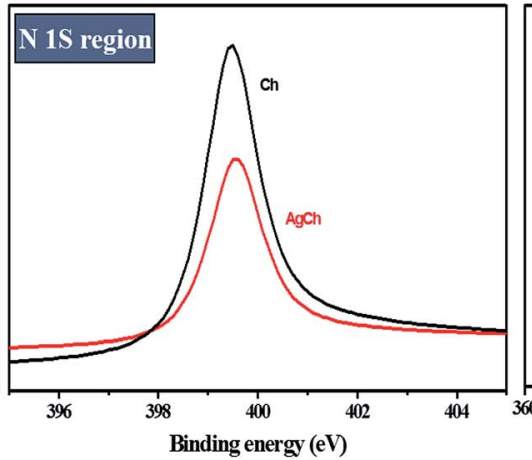

(c)

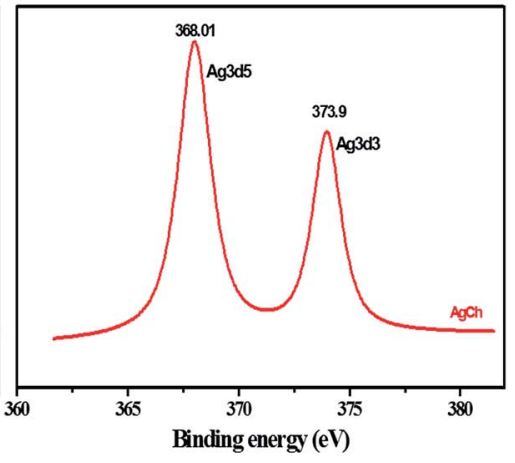

Fig. 4 High-resolution XPS spectra for (a) O 1s, (b) N 1s, and (c) Ag regions of the AgCh complex.

occur in the complexes prepared in the present study because of the substantial presence of both hydroxyl ions and different ligating functional groups in the chelating polymer.

The surface composition of the catalyst complexes was analysed by XPS. The changes observed in the spectrum of the $\mathrm{Ch}$ polymer after the formation of complexes can be seen for $\mathrm{AgCh}$ in Fig. 4. XPS before and after complexation comparison for Fe and $\mathrm{Cu}$ catalysts is shown in ESI, Fig. S2. $\dagger$ The intensity of the $\mathrm{O} 1 \mathrm{~s}$ and $\mathrm{N}$ 1s peak of Ch decreased after AgCh formation. In both regions, the peak shifted to slightly higher values of binding energy, which clearly indicates the transfer of electron density from $\mathrm{Ch}$ to Ag. As in the FTIR spectra, where the strong $\mathrm{N}-\mathrm{H}$ absorbance diminishes after complexation, the XPS spectrum reveals that the lone pair of electrons from the nitrogen atom of amine groups contributes to coordination of Ag. Fig. 4(c) confirms the presence of $\mathrm{Ag}$, and the two characteristic peaks at 368 and $373.9 \mathrm{eV}$ confirm the oxidation state of $\mathrm{Ag}$ to be +1 .

The TEM images of the Ch polymer presented in Fig. 5(a) show that the pristine polymer has a loose, fibrillar structure, indicating the presence of free polymer chains. The formation of the AgCh complex [Fig. 5(b) and (c)] induces a change in the
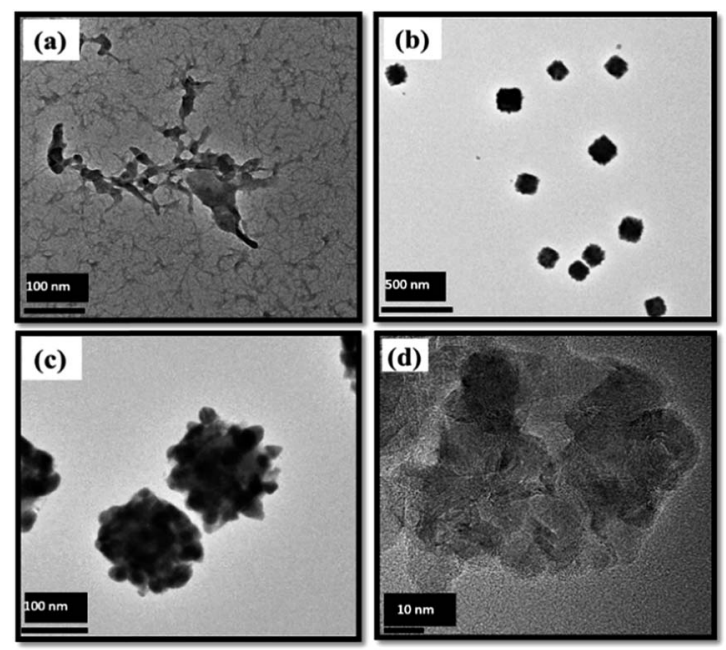

Fig. 5 TEM images of (a) Ch and (b-d) AgCh at different magnification. morphology, from fibrillar to uniform cube-like structures. These cubes with varying size between 100 to $200 \mathrm{~nm}$, are observed for AgCh only; no cube-like structures are observed for AgCh only; no cube-like structures are observed for the other metal-Ch complexes (Fig. S3, ESI $\dagger$ ). The cubes are suggested to form because of the tendency of the polymer to chelate metal atom in three-dimensional configurations.

\section{Discussion}

The activity of all the prepared catalysts is shown in Fig. 6 and Table 1. Zero conversion of the $\mathrm{CH}_{4}$ was observed when reaction was carried out without catalyst. Calculated moles, as present in their respective complex catalyst, of metal $(\mathrm{Ag}, \mathrm{Fe}, \mathrm{Cu})$ nitrates employed as catalysts were able to show a moderate activity. However, no methanol was produced showing complete selectivity towards formic acid. The pristine $\mathrm{Ch}$ produced a negligible amount of methanol $(12 \mu \mathrm{mol})$ indicating possibility of methanol formation with this material when employed as catalyst. Adding $\mathrm{AgNO}_{3}$ (which showed best activity among the tested metal nitrates) and $\mathrm{Ch}$ into the reaction mixture produced formic acid, surprisingly, but not methanol. This observation confirms metal nitrates dominates the reaction path way to formic acid. After metal complexation, there was an abrupt increase in methanol formation, along with other

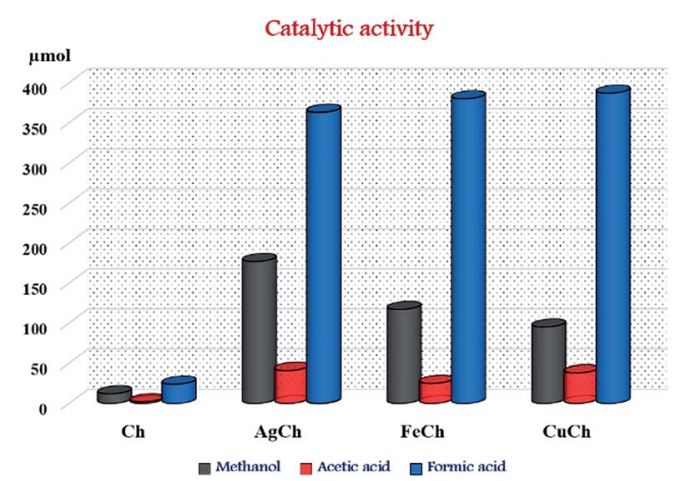

Fig. $6 \mathrm{CH}_{4}$ oxidation activity comparison of $\mathrm{AgCh}, \mathrm{FeCh}$ and $\mathrm{CuCh}$ catalysts. 
Table 1 Product quantification and percentage of $\mathrm{CH}_{4}$ conversion for different catalysts used in this work ${ }^{a}$

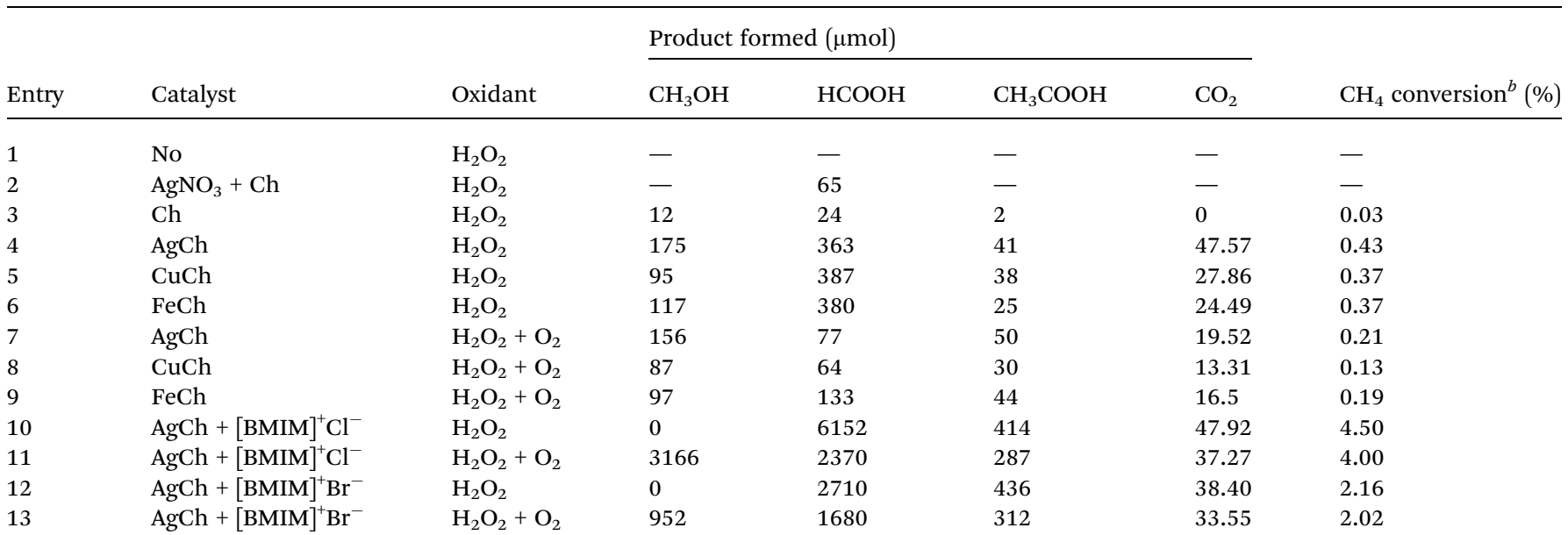

${ }^{a}$ Reaction conditions - catalyst: $0.15 \mathrm{~g}$, solvent: $15 \mathrm{~mL} \mathrm{DI} \mathrm{H}_{2} \mathrm{O}+5 \mathrm{~mL} 30 \% \mathrm{H}_{2} \mathrm{O}_{2}, P_{\left(\mathrm{CH}_{4}\right)}: 3 \times 10^{6} \mathrm{~Pa}$, temperature: $60{ }^{\circ} \mathrm{C}$, time: 3 h. ${ }^{b} \%$ conversion calculated using formula - total moles of oxygenates formed/initial moles of $\mathrm{CH}_{4} \times 100$.

byproducts including formic acid and acetic acid. These results imply that the metal-Ch complex synergistically makes an active component and thus, an active catalyst for the conversion of $\mathrm{CH}_{4}$ to its oxygenates. Among the prepared $\mathrm{AgCh}$, FeCh, and CuCh catalysts, AgCh showed the best performance, producing $175 \mu \mathrm{mol}$ of methanol and $227 \mu \mathrm{mol}$ of total oxygenated products for $0.15 \mathrm{~g}$ of the catalyst at a $\mathrm{CH}_{4}$ pressure of $3 \times 10^{6} \mathrm{~Pa}$. CuCh was more active than FeCh, nevertheless both these catalysts showed activity that was $\sim 20$ times lower than that of $\mathrm{AgCh}$ when the turnover number (TON) was considered. The concentration of over-oxidized products was higher than the concentration of methanol in all cases. Higher stability of Agcomplexes in peroxide medium might be responsible for best activity shown by AgCh compared to FeCh and CuCh. Agcomplexes reported to form a strong ionized intermediates where charge is normally a radical. ${ }^{22}$ These radical species, which are generated by homolytic cleavage nature of peroxide's O-O bond, are known to interact strongly with organic species to form chemicals. High activity of $\mathrm{AgCh}$ in this study also can be explained under similar mechanism in which radical species formed by $\mathrm{AgCh}$ complex in $\mathrm{H}_{2} \mathrm{O}_{2}$ medium can interact with hydrocarbon $\mathrm{CH}_{4}$ to form organic molecules like methanol, formic acid and etc. Though the formic acid and acetic acid are over oxidized products of methanol in this reaction, the $\mathrm{AgCh}$ complex, which shows high stability of radical species, was able to retain higher concentration of methanol in given time. $\mathrm{Cu}$ shows different oxidation states $\left(\mathrm{Cu}^{\mathrm{I}}\right.$ and $\left.\mathrm{Cu}^{\mathrm{II}}\right)$ and so do $\mathrm{Fe}\left(\mathrm{Fe}^{\mathrm{II}}\right.$ and $\mathrm{Fe}^{\mathrm{III}}$ ). Interconversion of these oxidation states reacting with $\mathrm{OH}^{\cdot}$ Produced by $\mathrm{H}_{2} \mathrm{O}_{2}$ during the reaction, ${ }^{23}$ causes easy over oxidation of methanol thereby giving more selectivity towards formic and acetic acid in case of these two metal complexes.

The activity of the AgCh catalyst was further studied by varying the amount catalyst from 0.03 to $0.15 \mathrm{~g}$ (Fig. 7(a)). Increasing the amount of the catalyst resulted in increased methanol formation. A catalyst loading of $0.03 \mathrm{~g}$ produced 48 $\mu \mathrm{mol}$ of methanol, which increased to $175 \mu \mathrm{mol}$ at a loading of
$0.15 \mathrm{~g}$. When a larger amount of AgCh was used, the products contained more formic acid than methanol. Higher amount of catalysts produces more methanol which may over oxidised to formic acid with the time and hence the more formic acid production suggesting that the catalyst was highly active. Investigations of the effect of reaction time, shown in Fig. 7(b), found that the maximum yield of liquid-phase products was obtained after $3 \mathrm{~h}$, after which the production of liquid-phase products decreased. These results suggest that reaction times longer than $3 \mathrm{~h}$ lead to deactivation of the catalyst. The overoxidation of $\mathrm{CH}_{4}$ to produce gaseous products may also cause the observed decrease in the content of liquid products at reaction times longer than $3 \mathrm{~h}$.

\section{Effects of $\mathrm{O}_{2}$ and $\mathrm{CO}_{2}$ on $\mathrm{CH}_{4}$ oxidation}

We studied in detail the effect of an additional oxidant, $\mathrm{O}_{2}$ (in the presence and absence of $\mathrm{H}_{2} \mathrm{O}_{2}$ ), on the single-step conversion of $\mathrm{CH}_{4}$ to methanol by our Ch catalysts. The results of the activity comparisons for each of the different catalysts are shown in Fig. 8(a) and Table 1, and showed trends that followed our earlier results. The AgCh performed well in the presence of $\mathrm{O}_{2}$, compared to $\mathrm{CuCh}$ and FeCh. Interestingly, the yield of oxygenates was comparatively less than in reactions conducted without $\mathrm{O}_{2}$. This finding suggests that when the reactor was purged with $\mathrm{O}_{2}$, the primary source of $\mathrm{O}$ atoms for use in the conversion of $\mathrm{CH}_{4}$ changes from $\mathrm{H}_{2} \mathrm{O}_{2}$ to $\mathrm{O}_{2}$. The observation of $\mathrm{H}_{2} \mathrm{O}_{2}$ consumption in both systems confirms that when $\mathrm{H}_{2} \mathrm{O}_{2}$ alone was used, it acts as an oxidant for $\mathrm{CH}_{4}$ conversion and when $\mathrm{O}_{2}$ was purged into reactor, $\mathrm{H}_{2} \mathrm{O}_{2}$ involves in the reaction as $\mathrm{O}$ atom active exchanger with $\mathrm{O}_{2}$ thereby minimizing its participation in over oxidizing side-reaction. This explanation was further supported by investigations of the amount of overoxygenated products generated compared to the amount of methanol, which showed that more methanol was produced in the $\mathrm{O}_{2}$-containing systems. The lower selectivity towards overoxidized products observed for systems that contained $\mathrm{O}_{2}$ 
(a)

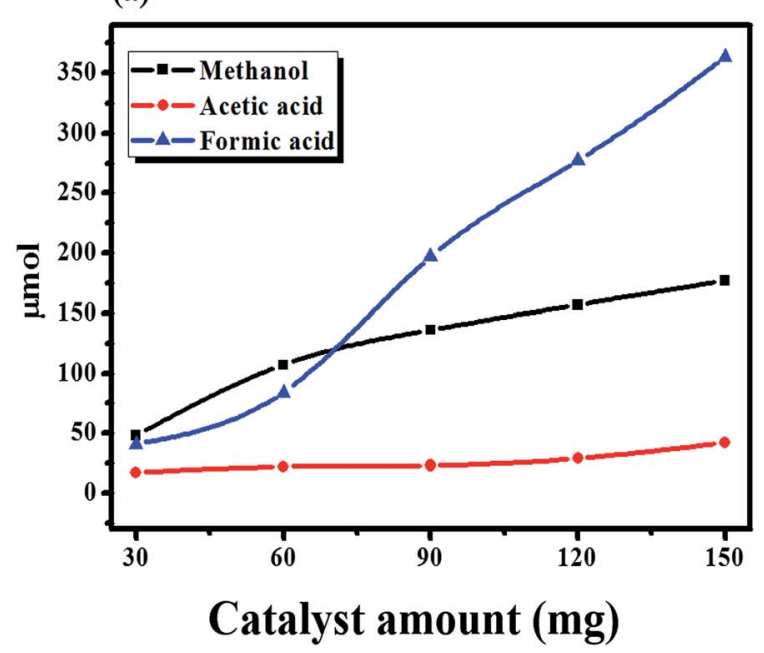

(b)

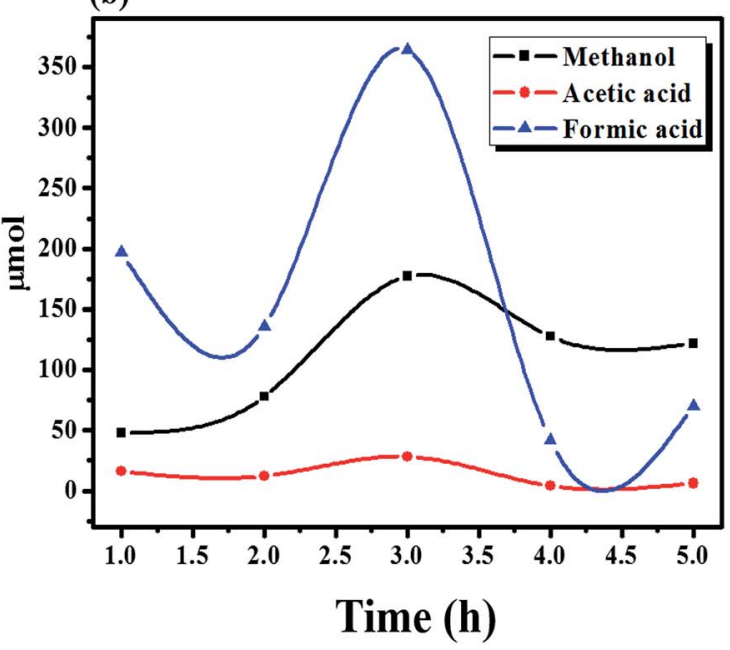

Fig. 7 The effect of (a) catalyst amount and (b) reaction time on the conversion of $\mathrm{CH}_{4}$ to its different oxygenate products.

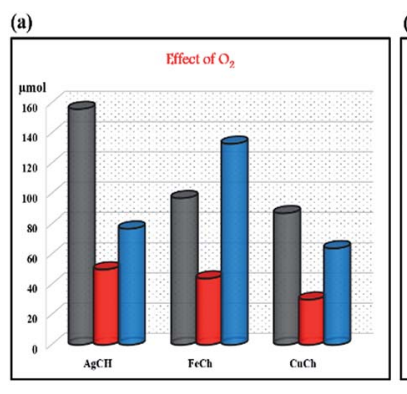

$\square$ Methanol $\square$ Acetic acid $\square$ Formic acld

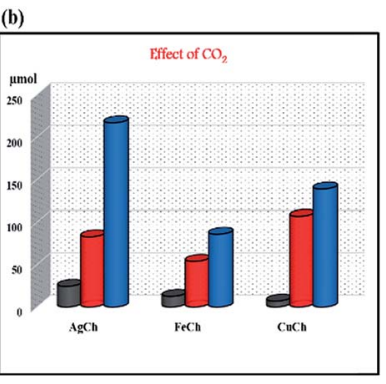

घMcthanol घAcetic acid $\square$ Formic acid
Fig. 8 The effect of (a) $\mathrm{O}_{2}$ and (b) $\mathrm{CO}_{2}$ on the conversion of $\mathrm{CH}_{4}$ to its different oxygenated products.

certainly suggests that there is a shift in source of $\mathrm{O}$ atoms from $\mathrm{H}_{2} \mathrm{O}_{2}$ to $\mathrm{O}_{2}$ in activating the catalytic system for the $\mathrm{CH}_{4}$ conversion reaction. When the reaction was carried out with $\mathrm{O}_{2}$ and no $\mathrm{H}_{2} \mathrm{O}_{2}$, a low amount of methanol was obtained. Hence, a combination of $\mathrm{O}_{2}$ and $\mathrm{H}_{2} \mathrm{O}_{2}$ is the optimal choice for higher selectivity towards methanol.

The effect of $\mathrm{CO}_{2}$ on the reaction is shown graphically in Fig. 8(b), which shows the amount of methanol obtained was low in all cases. These results are as expected since $\mathrm{CO}_{2}$ is a carboxylating agent. The acetic acid concentration was high when $\mathrm{CO}_{2}$ was present, suggesting that the direct carboxylation of methanol to acetic acid can occur. A comparison of the activity of the different catalysts again shows AgCh to be the best catalyst in all cases.

\section{Halide ion-containing ionic liquids as reaction promoters}

A recent study sought a suitable reaction promoter for the conversion of $\mathrm{CH}_{4}$ to its oxygenates. ${ }^{11}$ A previous report demonstrates that the addition of $\mathrm{Cu}$ to an $\mathrm{Au}-\mathrm{Pd} / \mathrm{TiO}_{2}$ catalyst $\left(\mathrm{AuPdCu} / \mathrm{TiO}_{2}\right.$ ) led to a 5 -fold increase in the $\mathrm{CH}_{4}$ conversion productivity, in line with other reports. ${ }^{24}$ The promoter's role is to activate $\mathrm{CH}_{4}$ by reducing the bond dissociation energy of the
$\mathrm{C}-\mathrm{H}$ bond. Halide anions are well known as $\mathrm{CH}_{4}$ activators, and scientists have made use of alkyl halides and halide salts for this purpose. Although the final $\mathrm{CH}_{4}$ conversion was increased when halide salts were used, it was still either relatively low or showed low selectivity towards oxygenates. ${ }^{\mathbf{8 , 1 1}}$ This lower performance was possibly because of a weaker attraction between the formed halide ions (from the halide salt) in the system and the catalyst. Halide ions remain in solution rather than associating strongly with the catalyst and therefore do not act efficiently during the catalytic cycle involved in $\mathrm{CH}_{4}$ activation. Hence, we suggest that the promoter's halide anion and the associated cations must bind strongly to the catalyst by means of a chemical bond. Thus, the formation of a suitable intermediate structure (as shown in Fig. 9(b and c)) can occur, providing a nearby source of promoter ions during the conversion reaction.

$\mathrm{CH}_{4}$ monooxygenase (MMO) is an enzyme that converts $\mathrm{CH}_{4}$ to methanol and oxidizes C1 to C5 hydrocarbons in nature. ${ }^{9}$ This enzyme is also highly active towards the oxidation of halogenated alkanes. ${ }^{25}$ Its structure includes Fe centers, which are coordinated with the $\mathrm{N}$ atoms of histidine and the $\mathrm{O}$ atoms of carboxylates and water. Our catalyst provides a similar environment to MMO, and the use of imidazolium-based halide ioncontaining ionic liquids as promoters provides easily accessible halide ions for triggering the formation of halogenated $\mathrm{CH}_{4}$. By analogy to the high activity of MMO for halogenated alkane oxidation and the similarity in catalyst environment between our Ch-based catalysts and MMO, we expect that the halogenated $\mathrm{CH}_{4}$ will be immediately oxidized. Another advantage of this system is the presence of $[\mathrm{BMIM}]^{+}$, which can act similarly to a reductase in some organic reactions. ${ }^{26}$ We suggest that this reductase action may provide a similar driving force for activation of $\mathrm{CH}_{4}$ as provided for MMO by nicotinamide adenine dinucleotide (NADH). Our experiments showed that 11-fold improvement in the conversion of $\mathrm{CH}_{4}$ to its oxygenates was achieved using these promoters. $[\mathrm{BMIM}]^{+} \mathrm{Cl}^{-}$and $[\mathrm{BMIM}]^{+} \mathrm{Br}^{-}$ were employed as reaction promoters with $\mathrm{AgCh}$, which had the 
(a)

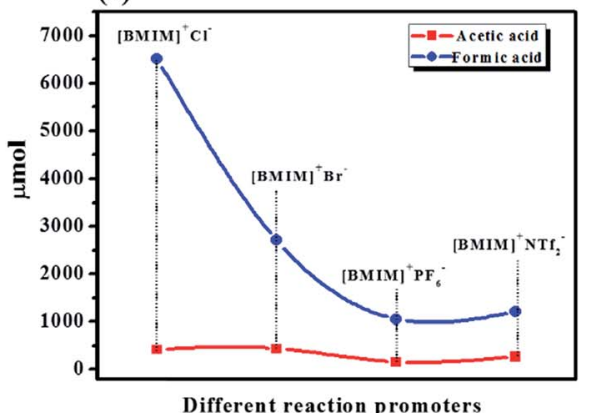

(b)

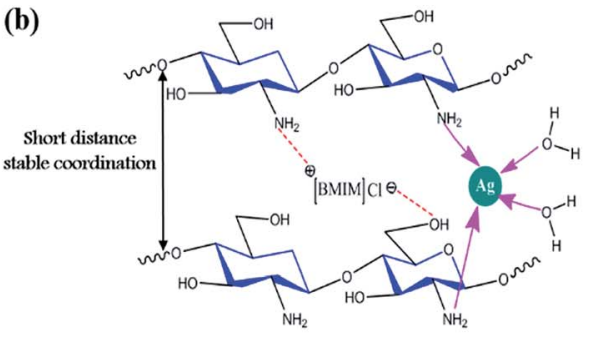

(c)

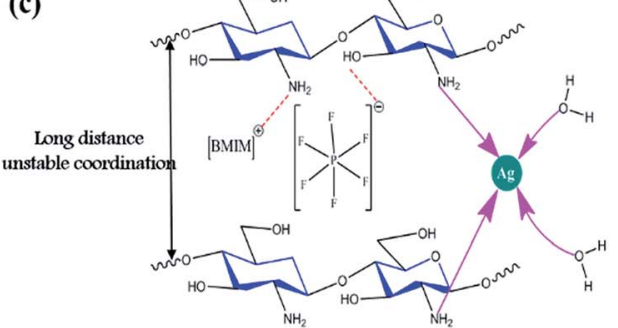

Fig. 9 (a) The effect of the different ionic liquids used as reaction promoters. (b and c) Possible structures of AgCh after interacting with ionic liquids of different size.

best performance in earlier tests compared to the other prepared catalyst complexes (entry no. 10 in Table 1). The $\mathrm{CH}_{4}$ conversion increased abruptly, with 11-fold and 5.5-fold increases for $[\mathrm{BMIM}]^{+} \mathrm{Cl}^{-}$and $[\mathrm{BMIM}]^{+} \mathrm{Br}^{-}$respectively. This finding suggests that $\mathrm{Cl}^{-}$ions are better halide promoters for the reaction with the AgCh catalyst. To confirm the improvement in activity was a result of the presence of halide anions, we also compared the performance of ionic liquid promoters with $\mathrm{PF}_{6}{ }^{-}$and $\mathrm{NTf}_{2}{ }^{-}$anions (shown in Fig. 9(a)), which are extensively used in many gas phase reactions. ${ }^{27,28}$ Even though these anions were effective promoters, their performance was considerably lower than that of the halide ions. These results also demonstrate the high possibility of cation activity in the conversion reaction. The $\mathrm{PF}_{6}{ }^{-}$and $\mathrm{NTf}_{2}{ }^{-}$anions are larger than the halide anions, which affects the coordination structure and stability of catalyst, as shown in Fig. 9(b and c). A control experiment was done using only $\left[[\mathrm{BMIM}]^{+} \mathrm{Cl}^{-}\right.$. The only observed product was formic acid $(2085 \mu \mathrm{mol})$, which indicated that the $[\mathrm{BMIM}]^{+} \mathrm{Cl}^{-}$was three times less effective when used alone than when it was used as a promoter with the catalyst. These results provide evidence that the ionic liquids form a structure with the catalyst that favors higher $\mathrm{CH}_{4}$ conversion. Hence, our attempt to establish an intermediate structure between catalysts and promoter was effective in achieving a higher conversion of $\mathrm{CH}_{4}$. The maximum conversion of $\mathrm{CH}_{4}$ observed after using ionic liquids as promotors is $4.5 \%$. When compared to traditional catalysis, the achieved conversion is very low. However for $\mathrm{CH}_{4}$ conversion into its oxygenates via one-step, the $4.5 \%$ conversion is still noteworthy. A tabulated comparison of $\mathrm{CH}_{4}$ conversion and methanol selectivity from the literature is shown in Table S3. $\dagger$ It can be seen that the performance of our catalyst at lower temperature is comparable to other reports which are done at higher temperatures.

Finally, we combined the findings of our optimizations by testing the influence of oxygen and $\mathrm{CO}_{2}$ on the $\mathrm{CH}_{4}$ conversion reaction with the AgCh catalyst, the $[\mathrm{BMIM}]^{+} \mathrm{Cl}^{-}$promoter and the $\mathrm{H}_{2} \mathrm{O}_{2}$ co-oxidant. The results, shown in Fig. 10, indicate that the total conversion was lower when this catalyst system was used without $\mathrm{O}_{2}$ or $\mathrm{CO}_{2}$. However, the addition of $\mathrm{O}_{2}$ resulted in the production of $3166 \mu \mathrm{mol}$ of methanol, (entry no. 9 in Table 1) which is $\sim 18$ times higher than the yield from AgCh alone. This comparison reveals that the use of $\mathrm{O}_{2}$ reduces the overoxidation of methanol, and hence a combination of $\mathrm{H}_{2} \mathrm{O}_{2}$ and $\mathrm{O}_{2}$ is the best oxidant for methanol synthesis. However, the ionic liquid cation was responsible for the production of $\sim 1500$ $\mu \mathrm{mol}$ of formic acid. The selectivity towards methanol was found to be $54 \%$ in this case as highest selectivity for methanol detected in this work. The methanol selectivity comparison with the literature is shown in Table S3† which explains the 54\% selectivity was worthy when compared previous reports. When $\mathrm{CO}_{2}$ was added, no methanol was observed. Instead, $3832 \mu \mathrm{mol}$ of formic acid was produced, which is more than double compared to the amount of formic acid formed in $\mathrm{O}_{2}$ purged system $(\sim 1500 \mu \mathrm{mol})$. This finding suggests that the

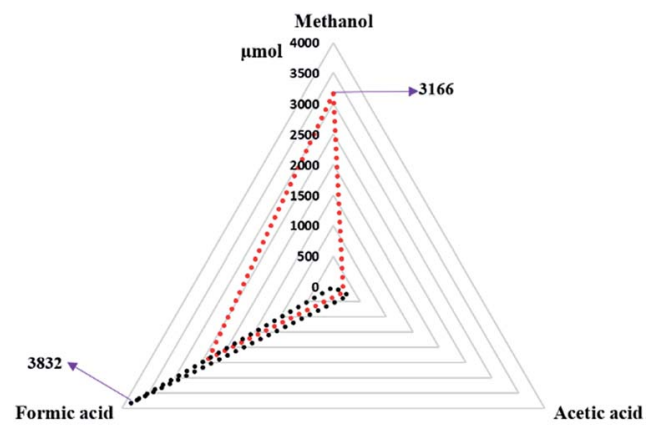

$\bullet \ldots . . \mathrm{AgCh}+[\mathrm{BMIM}]+\mathrm{Cl}+\mathrm{O}_{2} \quad \ldots . \cdots \mathrm{AgCh}+[\mathrm{BMIM}]^{+} \mathrm{Cl}+\mathrm{CO}_{2}$

Fig. $10 \mathrm{CH}_{4}$ conversion activity of $\mathrm{AgCh}$ and $[\mathrm{BMIM}]^{+} \mathrm{Cl}^{-}$combinations with different gaseous oxidants $\left(\mathrm{O}_{2}\right.$ and $\left.\mathrm{CO}_{2}\right)$. 
combination of catalyst, promoter and $\mathrm{CO}_{2}$ presents a strong $\mathrm{CH}_{4}$ carbonylation environment.

\section{Conclusions}

A catalytic AgCh complex for conversion of $\mathrm{CH}_{4}$ to its oxygenates was prepared and fully characterized. The complex contained $\mathrm{Ag}(\mathrm{I})$, which provides the redox properties necessary to undergo the inorganic nucleophilic reactions involved in the conversion of $\mathrm{CH}_{4}$ to methanol. The suitability of $\mathrm{Ag}$ for this conversion was demonstrated by comparing AgCh with catalysts prepared using various metal atoms ( $\mathrm{Fe} \& \mathrm{Cu}$ ). Efforts to identify the best oxidant revealed that $\mathrm{H}_{2} \mathrm{O}_{2}$ alone led to a higher $\mathrm{CH}_{4}$ conversion percentage than a combination of $\mathrm{O}_{2}$ and $\mathrm{H}_{2} \mathrm{O}_{2}$. This result was suggested to occur because of the shifting of $\mathrm{O}$ utilization source from $\mathrm{H}_{2} \mathrm{O}_{2}$ to $\mathrm{O}_{2}$, which renders rate of reaction. We determined the best environment to maximize methanol selectivity in our study of ionic liquids with halide anions as promoters. We found that a combination of $\mathrm{AgCh}$ with [BMIM $]^{+} \mathrm{Cl}^{-}$and $\mathrm{H}_{2} \mathrm{O}_{2}$ increased the $\mathrm{CH}_{4}$ conversion 11-fold, but only over oxidized products were observed. The increased conversion confirmed the utility of our strategy to establish an interaction between the catalysts and the promoter. Finally, a system using a combination of $\mathrm{H}_{2} \mathrm{O}_{2}, \mathrm{O}_{2}, \mathrm{AgCh}$ and $[\mathrm{BMIM}]^{+} \mathrm{Cl}^{-}$showed the best selectivity for methanol and a 13fold improvement in the yield of methanol compared to the system with $\mathrm{H}_{2} \mathrm{O}_{2}$ alone, producing $3166 \mu \mathrm{mol}$ of methanol. As an extended work, experiments are ongoing in our laboratory to establish a cyclic radicle mechanism among the added halide anions and $\mathrm{CH}_{4}$ in order to invent a new green feasible method for this oxidation reaction.

\section{Acknowledgements}

This work was supported by the Energy Efficiency \& Resources (No. 20163010092210) of the Korea Institute of Energy Technology Evaluation and Planning (KETEP) grant funded by the Korea government Ministry of Trade, Industry \& Energy and this work was supported by Nano-Material Fundamental Technology Development (2016M3A7B4909370) through National Research Foundation of Korea (NRF) funded by the Ministry of Science, ICT and Future Planning.

\section{Notes and references}

1 J. Galuszka, R. Pandey and S. Ahmed, Catal. Today, 1998, 46, 83-89.

2 J. G. Seo, M. H. Youn, Y. Bang and I. K. Song, Int. J. Hydrogen Energy, 2011, 36, 3505-3514.

3 M. Rezaei, S. M. Alavi, S. Sahebdelfar and Z.-F. Yan, J. Nat. Gas Chem., 2006, 15, 327-334.

4 K. C. Waugh, Catal. Today, 1992, 15, 51-75.

5 M. Behrens, F. Studt, I. Kasatkin, S. Kuhl, M. Havercker, F. Abild-pedersen, S. Zander, F. Girgsdies, P. Kurr, B. Kniep, M. Tovar, R. W. Fischer, J. K. Norskow and R. Schlogl, Science, 2012, 336, 893-898.
6 M. V. Kirillova, M. L. Kuznetsov, P. M. Reis, J. A. L. Da Silva, J. J. R. Fraústo Da Silva and A. J. L. Pombeiro, J. Am. Chem. Soc., 2007, 129, 10531-10545.

7 R. A. Periana, Science, 1998, 280, 560-564.

8 Q. Yuan, W. Deng, Q. Zhang and Y. Wang, Adv. Synth. Catal., 2007, 349, 1199-1209.

9 M. H. Ab Rahim, R. D. Armstrong, C. Hammond, N. Dimitratos, S. J. Freakley, M. M. Forde, D. J. Morgan, G. Lalev, R. L. Jenkins, J. A. Lopez-Sanchez, S. H. Taylor and G. J. Hutchings, Catal. Sci. Technol., 2016, 6, 3410-3418.

10 C.-C. Liu, C.-Y. Mou, S. S.-F. Yu and S. I. Chan, Energy Environ. Sci., 2016, 9, 1361-1374.

11 C. Hammond, M. M. Forde, M. H. Ab Rahim, A. Thetford, Q. He, R. L. Jenkins, N. Dimitratos, J. A. Lopez-Sanchez, N. F. Dummer, D. M. Murphy, A. F. Carley, S. H. Taylor, D. J. Willock, E. E. Stangland, J. Kang, H. Hagen, C. J. Kiely and G. J. Hutchings, Angew. Chem., Int. Ed., 2012, 51, 5129-5133.

12 M. Sun, E. Abou-Hamad, A. J. Rossini, J. Zhang, A. Lesage, H. Zhu, J. Pelletier, L. Emsley, V. Caps and J.-M. Basset, J. Am. Chem. Soc., 2013, 135, 804-810.

13 K. Narsimhan, V. K. Michaelis, G. Mathies, W. R. Gunther, R. G. Griffin and Y. Román-Leshkov, J. Am. Chem. Soc., 2015, 137, 1825-1832.

14 K. Otsuka, M. Hatano and T. Komatsu, Catal. Today, 1989, 4, 409-419.

15 X. Wang, Y. Du and H. Liu, Carbohydr. Polym., 2004, 56, 2126.

16 Z. Guo, L. L. Henry, V. Palshin and E. J. Podlaha, J. Mater. Chem., 2006, 16, 1772-1777.

17 Y. L. Wei, K. W. Chen and H. P. Wang, J. Vac. Sci. Technol., B: Microelectron. Nanometer Struct., 2009, 27, 1385.

18 J. N. Nian, S. A. Chen, C. C. Tsai and H. Teng, J. Phys. Chem. $B, 2006,110,25817-25824$.

19 P. Kumar, R. Nagarajan and R. Sarangi, J. Mater. Chem. C, 2013, 1, 2448.

20 M. Wilke, F. Farges, P. E. Petit, G. E. Brown and F. Martin Jr, Am. Mineral., 2001, 86, 714-730.

21 C. Lamberti, S. Bordiga, F. Bonino, C. Prestipino, G. Berlier, L. Capello, F. D. Acapito, F. X. Llabres i Xamena and A. Zecchina, Phys. Chem. Chem. Phys., 2003, 5, 4502-4509.

22 H. Yin, D. L. Hachey and N. A. Porter, J. Am. Soc. Mass Spectrom., 2001, 12, 449-455.

23 E. Vidrio, H. Jung and C. Anastasio, Atmos. Environ., 2008, 42(18), 4369-4379.

24 M. D. Pham, Y. P. Lin, Q. Van Vuong, P. Nagababu, B. T. A. Chang, K. Y. Ng, C. H. Chen, C. C. Han, C. H. Chen, M. S. Li, S. S. F. Yu and S. I. Chan, Biochim. Biophys. Acta, Proteins Proteomics, 2015, 1854, 1842-1852.

25 R. L. Lieberman and A. C. Rosenzweig, Crit. Rev. Biochem. Mol. Biol., 2004, 39, 147-164.

26 Y. Oh and X. Hu, Chem. Commun., 2015, 51, 13698-13701. 27 A. A. Chaugule, A. H. Tamboli, F. A. Sheikh, W. J. Chung and H. Kim, J. Mol. Liq., 2015, 208, 314-321.

28 A. A. Chaugule, A. H. Tamboli and H. Kim, $R S C A d v ., 2016,6$, 42279-42287. 